\title{
Study of correlation between fetomaternal outcome with placental location at a tertiary hospital
}

\author{
Anita Sitimani, Balumuri Pooja Sai*, Bandamma Narendra S., Prema Prabhudev
}

Department of Obstetrics and Gynecology, SSIMS and RC, Davangere, Karnataka, India

Received: 25 January 2022

Accepted: 22 February 2022

\section{*Correspondence:}

Dr. Balumuri Pooja Sai,

E-mail: poojabalumuri11@gmail.com

Copyright: (c) the author(s), publisher and licensee Medip Academy. This is an open-access article distributed under the terms of the Creative Commons Attribution Non-Commercial License, which permits unrestricted non-commercial use, distribution, and reproduction in any medium, provided the original work is properly cited.

\begin{abstract}
Background: The site of implantation and location of placenta can affect the blood supply of placenta which is likely important determinant of placental blood flow and pregnancy outcome.

Methods: In our study 240 pregnant women of $19-35$ years, singleton $\geq 28$ weeks underwent ultrasound examination for placental localization.

Results: Majority of pregnant women were from 21-25 years age, multigravida and placental location in majority was lateral. Adverse events were PROM, preeclampsia/ eclampsia, IUGR, preterm birth was noted with lateral location of placenta.

Conclusions: A significant association was noted between lateral placentation of placenta and adverse fetomaternal outcome. Ultrasound examination can be used as non-invasive predictor of adverse pregnancy and neonatal outcomes.
\end{abstract}

Keywords: Lateral placentation, Placental location, Fetomaternal outcome, Ultrasound examination

\section{INTRODUCTION}

Placenta is an important fetal organ with metabolic, immunological, endocrinal, respiratory, and nutritional functions. The placenta is crucial for foetal growth and survival, performing the most important functions of many somatic organs before birth. The site of implantation and as a result of it the location of the placenta can affect the blood supply of placenta. This in turn can affect the outcome of pregnancy. ${ }^{1}$

During pregnancy, uterine blood supply is not uniformly distributed. The uterine site of placental implantation is an important determinant of placental blood flow. The site of implantation and resultant location of the placenta within the uterus are likely important determinants of placental blood flow and therefore pregnancy success. ${ }^{2}$ Placental location has been found to correlate with foetal position and presentation, length of gestation, course of labour, presence of preeclampsia, intrauterine growth restriction (IUGR) and pregnancy outcome. ${ }^{2}$

Placental location was reported to be related to birthweight among singleton pregnancies, mainly due to decreased blood supply to lateral and fundal placentas. ${ }^{3,4}$ Unilateral placental implantations (placentas where the bulk of the placenta is implanted over the right or left lateral aspect of the uterus) have been linked with an increased incidence of preeclampsia, fetal distress in labor, abdominal deliveries and intrauterine growth retardation (IUGR). ${ }^{5,6}$ Anterior placental implantation is associated with an increased risk of pregnancy-induced hypertension, gestational diabetes mellitus, placental abruption, intrauterine growth retardation and intrauterine foetal death. $^{7}$

Present study was aimed to study correlation between fetomaternal outcome with placental location at a tertiary hospital. 


\section{METHODS}

Present study was hospital based, prospective, observational study, conducted in department of obstetrics and gynaecology, in a tertiary care hospital. Study duration was of 2 years (July 2019 to June 2021). Prior to enrolment of patients, ethical committee clearance was obtained.

\section{Inclusion criteria}

Pregnant women 19-35 years, singleton pregnancy of $\geq 28$ weeks, willing to participate were included in study.

\section{Exclusion criteria}

Pregnant women with past or present medical and obstetric disorders, multiple gestation, chronic renal disease, chronic hypertension, low lying placenta and those who are not willing for follow up were excluded from study.

Study was explained and a written informed consent was taken. Baseline information such as maternal age, parity and medical history, previous obstetric history, previous USG findings were noted. Complete general physical, systemic and obstetric examination was done and findings were noted.

All pregnant women underwent ultrasound examination, after 28 weeks of gestation using Toshiba Nimio ultrasound machine with frequency $6.5 \mathrm{MHz}$ transvaginal transducer and $5 \mathrm{MHz}$ transabdominal transducer. Placental location was noted as anterior, posterior, fundal, lateral and low-lying placenta-depending on where $>75 \%$ of the placental mass located. Follow up kept till delivery.

The outcome variables included pre-eclampsia or eclampsia, IUGR, antepartum hemorrhage, oligohydramnios, preterm prelabor rupture of membranes (PPROM), term prelabor rupture of membranes (TPROM), preterm labor, gestation at delivery, intrauterine fetal demise, duration of third stage of labor, fetal distress in labor (who eventually had caesarean delivery), postpartum hemorrhage and manual removal of placenta (MROP). We also studied neonatal outcomes, such as mean birth weight, Apgar $<7$ at 1 or 5 minutes and early neonatal death.

Data was collected and compiled using Microsoft Excel. Statistical analysis was done using SPSS 21. Chi-square test was used for categorical data. $\mathrm{P}<0.05$ is considered as statistically significant.

\section{RESULTS}

During study period 240 pregnant women completed present study. Majority of pregnant women were from 2125 years age group (43.33\%) followed by $26-30$ years age group $(40 \%)$, majority were gravida $2-3(39.17 \%)$ and primigravida $(38.33 \%)$. According to placental location majority were lateral $(35.83 \%)$ followed by anterior $(26.67 \%)$, posterior $(20 \%)$ and fundal $(17.5 \%)$.

Table 1: General characteristics.

\begin{tabular}{|lll|}
\hline Characteristics & No. of patients & Percentage (\%) \\
\hline Age (years) & & \\
\hline$\leq 20$ & 19 & 7.92 \\
\hline $21-25$ & 104 & 43.33 \\
\hline $26-30$ & 96 & 40 \\
\hline $31-35$ & 21 & 8.75 \\
\hline Gravid status & & \\
\hline 1 & 92 & 38.33 \\
\hline $2-3$ & 94 & 39.17 \\
\hline 4 or more & 54 & 22.50 \\
\hline $\begin{array}{l}\text { Placental } \\
\text { location }\end{array}$ & & \\
\hline Lateral & 86 & 35.83 \\
\hline Anterior & 64 & 26.67 \\
\hline Posterior & 48 & 20 \\
\hline Fundal & 42 & 17.50 \\
\hline
\end{tabular}

In present study adverse maternal events were PROM (22.92\%), preeclampsia/ eclampsia (15.83\%), oligohydramnios (12.92\%), preterm PROM (10\%), antepartum hemorrhage $(6.25 \%)$, malpresentations $(5.83 \%)$, preterm labor $(5.42 \%)$. Majority of adverse events were noted in pregnant women with lateral location of placenta and association was statistically significant $(\mathrm{p}<0.05)$.

In present study mean APGAR score at 1 min was $8.42 \pm 1.22$, mean APGAR score at 5 min was 9.02 \pm 0.5 and mean baby weight $(\mathrm{kg})$ was $2.6 \pm 0.34 \mathrm{kgs}$. Adverse neonatal events were IUGR $(5 \%)$, preterm birth $(15.42 \%)$, IUFD/ still birth $(1.25 \%)$ and required NICU admission $(6.25 \%)$. Majority of adverse events were noted in pregnant women with lateral location of placenta and association was statistically significant $(\mathrm{p}<0.05)$.

Table 2: Maternal complications noted with relation of placenta.

\begin{tabular}{|c|c|c|c|c|c|}
\hline Maternal complication & $\begin{array}{l}\text { Lateral, }(\mathrm{n}=\mathbf{8 6}) \\
(\%)\end{array}$ & $\begin{array}{l}\text { Anterior, } \\
(n=64)(\%)\end{array}$ & $\begin{array}{l}\text { Posterior, } \\
(\mathrm{n}=48)(\%)\end{array}$ & $\begin{array}{l}\text { Fundal, } \\
(n=42)(\%)\end{array}$ & Total (\%) \\
\hline PROM & $15(17.44)$ & $11(17.19)$ & $22(45.83)$ & $7(16.67)$ & $55(22.92)$ \\
\hline Preeclampsia/ eclampsia & $22(25.58)$ & $8(12.5)$ & $5(10.42)$ & $3(7.14)$ & $38(15.83)$ \\
\hline Oligohydramnios & $14(16.28)$ & $8(12.5)$ & $4(8.33)$ & $5(11.9)$ & $31(12.92)$ \\
\hline Preterm PROM & $13(15.12)$ & $5(7.81)$ & $3(6.25)$ & $3(7.14)$ & $24(10)$ \\
\hline
\end{tabular}

Continued. 


\begin{tabular}{|c|c|c|c|c|c|}
\hline Maternal complication & $\begin{array}{l}\text { Lateral, }(\mathrm{n}=86) \\
(\%)\end{array}$ & $\begin{array}{l}\text { Anterior, } \\
(n=64)(\%)\end{array}$ & $\begin{array}{l}\text { Posterior, } \\
(\mathrm{n}=48)(\%)\end{array}$ & $\begin{array}{l}\text { Fundal, } \\
(\mathrm{n}=\mathbf{4 2})(\%)\end{array}$ & Total (\%) \\
\hline Antepartum hemorrhage & $11(12.79)$ & $2(3.13)$ & $1(2.08)$ & $1(2.38)$ & $15(6.25)$ \\
\hline Malpresentations & $9(10.47)$ & $2(3.13)$ & $3(6.25)$ & 0 & $14(5.83)$ \\
\hline Preterm labor & $9(10.47)$ & $2(3.13)$ & $1(2.08)$ & $1(2.38)$ & $13(5.42)$ \\
\hline
\end{tabular}

Table 3: Neonatal outcomes associated with placental location.

\begin{tabular}{|c|c|c|c|c|c|}
\hline Variables & $\begin{array}{l}\text { Lateral, }(\mathrm{n}=86) \\
(\%)\end{array}$ & $\begin{array}{l}\text { Anterior, } \\
(\mathrm{n}=64)(\%)\end{array}$ & $\begin{array}{l}\text { Posterior, } \\
(\mathrm{n}=48)(\%)\end{array}$ & $\begin{array}{l}\text { Fundal, } \\
(\mathrm{n}=\mathbf{4 2})(\%)\end{array}$ & Total $(\%)$ \\
\hline IUGR & $8(9.3)$ & $2(3.13)$ & $1(2.08)$ & $1(2.38)$ & $12(5)$ \\
\hline Preterm birth & $22(25.58)$ & $7(10.94)$ & $4(8.33)$ & $4(9.52)$ & $37(15.42)$ \\
\hline IUFD/still birth & $2(2.33)$ & 0 & $1(2.08)$ & 0 & $3(1.25)$ \\
\hline APGAR score at 1 min & $8.02 \pm 1.06$ & $8.23 \pm 1.4$ & $8.21 \pm 1.24$ & $8.25 \pm 1.02$ & $8.42 \pm 1.22$ \\
\hline APGAR score at $5 \mathrm{~min}$ & $8.55 \pm 1.01$ & $8.65 \pm 0.91$ & $8.72 \pm 1.01$ & $8.46 \pm 1.2$ & $9.02 \pm 0.5$ \\
\hline Mean baby weight (kg) & $2.39 \pm 0.63$ & $2.61 \pm 0.35$ & $2.49 \pm 0.24$ & $2.5 \pm 0.43$ & $2.6 \pm 0.34$ \\
\hline NICU admission required & $6(6.98)$ & $4(6.25)$ & $3(6.25)$ & $2(4.76)$ & $15(6.25)$ \\
\hline
\end{tabular}

\section{DISCUSSION}

Trans-abdominal sonographic assessment of placental location is one of the standard components of the basic obstetrical ultrasound examination. Placental location is classified as central (anterior and posterior), unilateral (right lateral, left lateral), fundal and low lying (within 2 $\mathrm{cm}$ of internal OS).

When the placenta is centrally located, the utero placental blood flow needs are met by equal contribution from both uterine arteries. However, when the placenta is laterally located, in the majority of the patients, the utero placental blood flow needs are met primarily by one of the uterine arteries, with some contribution by the other uterine artery via collateral circulation. This degree of collateral circulation, however, may not be the same in all patients and deficient contribution may facilitate the development of preeclampsia, IUGR or both.

Patil et al studied 200 pregnant women, the frequency of central placentation was $166(82.8 \%)$, lateral placentation $32(16.2 \%)$ and placenta previa was $2(1 \%){ }^{8}$ Central placentation had an abnormal outcome in 77(46.3\%) and lateral placentas with abnormal outcome were 18 (57.2\%). Abnormal neonatal outcomes like IUGR (16\%), preterm birth $(31 \%)$, and intrauterine death $(3 \%)$ were more in lateral placentation. The number of central placentas having NICU admissions were (14.60\%) and lateral placentas with NICU admissions were (29.30\%). Additionally, we also found an association between unilateral implantation and low Apgar scores at 1 and 5 minutes in comparison with centrally located placenta.

Cheema et al studied 1000 pregnant females, mean maternal age was $26.51 \pm 4.25$ years, mean period of gestation was $38.08 \pm 2.30$ weeks. $^{9}$ The placenta was located anteriorly in $67 \%$, posteriorly in $31 \%$ and laterally in $2 \%$. No significant association was noted between the location of the placenta and mortality of baby born to them. Mean baby weight was significantly different among the three types of placental localizations $(p=0.037)$. There was a significant association between the location of the placenta and mean birth weight of the baby. Future studies should be done on larger populations at multiple centres.

Dhingra et al studied 200 pregnant women, $42 \%$ of placenta were situated in fundus, $30 \%$ were anterior, $18 \%$ were lateral, $8 \%$ were posterior and $2 \%$ were low lying. ${ }^{10}$ Gestational hypertension was present in $22 \%, 13 \%, 12 \%$ in lateral, anterior and posterior placental location respectively. Preeclampsia was seen in $22 \%$ in lateral placental location. Preterm labour, PROM, low birth weight and NICU admission were common in posterior and lateral placental location. There was statistically significant association between low lying, posterior and lateral placental location and adverse maternal fetal outcomes.

Kadium et al evaluated the relationship between placental location and occurrence of pregnancy induced hypertension. ${ }^{11}$ The 81 women diagnosed with pregnancy induced hypertension (gestational hypertension, preeclampsia, eclampsia) according to ACOG and 81 normotensive women in their third trimester were examined with ultrasound for localisation of placenta. Out of 162 patients, the most common age of presentation was 20 to 25 years. $69.13 \%$ of PIH women had laterally implanted placenta and $30.9 \%$ had centrally located placenta. Whereas in normotensives $74.1 \%$ had centrally located placenta and $25.9 \%$ had laterally located placenta. They noted a significant association between site of implantation of placenta and the occurrence of PIH. The efficacy of using placental laterality by ultrasonogram as a predictor of PIH has a sensitivity of $78.1 \%$ which though low is better than most other tests, specificity of $74 \%$ and positive predictive value of $73 \%$. However, it has a low negative predictive value of $70.5 \%$ when compared with other tests. Laterally located placenta is 6.4 times more commonly seen in women with pregnancy induced hypertension when compared to that in normotensive women. 
Nair studied, 450 singleton pregnancies, frequency of central placenta was $377(83.8 \%)$ and lateral placenta in 73 $(16.2 \%) .{ }^{12}$ Central placentation had an abnormal outcome in $182(48.3 \%)$, lateral placentas with abnormal outcome were $44(60.3 \%)$. Abnormal maternal outcomes like hypertensive disorders $(33.3 \%)$, intra uterine growth restriction $(10.2 \%)$, antepartum haemorrhage $(25 \%)$, preterm birth $(16.3 \%)$ were more in lateral placentation. The number of central placentas having NICU admissions were $62(16.4 \%)$ and lateral placenta with NICU admissions were $19(26 \%)$. There was a significant association between lateral placentation and abnormal pregnancy and neonatal outcomes.

Uikey et al studied 102 pregnant women, $80.9 \%$ were from lateral placenta group and only $19.1 \%$ were from central placenta. ${ }^{13}$ Sensitivity of this as screening test for preeclampsia was $80.9 \%$ while specificity was $58 \%$, Odds ratio being 5.875 . In predicting preeclampsia, lateral placenta had a meaningful effect with $\mathrm{p}<0.001$. Placental laterality, as determined by USG between 18-24 weeks of gestation, is a simple and cost-effective screening test for development of preeclampsia.

Posterior placental location is less efficient and associated with preterm labour, intrauterine demise (IUD) and stillbirth. This was mainly due to uneven blood supply because of the longer, thicker anatomy of posterior wall of pregnant uterus. ${ }^{14}$ Torricelli et al and Cho et al found significant association between preterm labour and posterior placental location $(\mathrm{p}<0.001) .{ }^{15,16}$

Faizi et al studied 620 pregnant women, $44.1 \%$ had anterior, $27.2 \%$ had posterior, $15.8 \%$ had fundal, $9.8 \%$ had lateral placentae and $2.9 \%$ had placenta previa as per the last scan done at 28 weeks. ${ }^{17}$ Pre-eclampsia $(27.9 \%)$ and antepartum hemorrhage $(19.7 \%)$ were more common in lateral placenta whereas term prelabor rupture of membranes $(11.2 \%)$ was more common in fundal placenta and these findings were statistically significant. The incidence of IUGR was also found to be higher in patients with lateral $(16.4 \%)$ and posteriorly (16\%) implanted placenta although there was no statistically significant association.

Magann et al analyzed 3336 pregnancies and noted that low placental implantation was associated with an increased risk of preterm labor, preterm delivery and a reduced risk of postpartum hemorrhage, and of a macrosomic fetus. ${ }^{18}$ High lateral implantation was associated with low Apgar scores. Fetal growth restriction (FGR) is often the result of placental insufficiency and is characterized by insufficient transplacental transport of nutrients and oxygen. The diagnosis of fetal growth restriction (FGR) has for long mainly be based on birth weight below a reference cut-off, most commonly the $10^{\text {th }}$ percentile. $^{19}$

\section{Limitations}

Further research is required to confirm this observation and to confirm whether pregnancies with lateral placental location are associated with adverse outcomes and whether monitoring of those pregnancies can be helpful to prevent complications.

\section{CONCLUSION}

A significant association was noted between lateral placentation of placenta and adverse fetomaternal outcome. Ultrasound examination can be used as noninvasive predictor of adverse pregnancy and neonatal outcomes.

Funding: No funding sources

Conflict of interest: None declared

Ethical approval: The study was approved by the Institutional Ethics Committee

\section{REFERENCES}

1. Jauniaux E, Watson AL, Hempstock J. Onset of maternal arterial blood flow and placental oxidative stress. A possible factor in human early pregnancy failure. Am J Pathol. 2000;157(6):2111-22.

2. Kalanithi LE, Illuzzi JL, Nossov VB. Intrauterine growth restriction and placental location. J Ultrasound Med. 2007;26(11):1481-9.

3. Seckin KD. Is lateral localisation of placenta a risk factor for adverse perinatal outcomes? J Obstetr Gynaecol. 2015;35:696-8.

4. Granfors M, Stephansson O. Placental location and pregnancy outcomes in nulliparous women: A population-based cohort study. Acta obstetricia et gynecologica Scandinavica. 2019;98(8):988-96.

5. Gonser M, Tillack N, Pfeiffer KH, Mielke G. Placental location and incidence of preeclampsia. Ultraschall Med. 1996;17:236-8.

6. Vaillant P, Best MC, Cynober E, Devulder G. Pathological uterine readings when the placenta is laterally situated. J Gynecol Obstet Biol Reprod. 1993;22:301-7.

7. Zia S. Placental location and pregnancy outcome. J Turkish-German Gynecol Assoc. 2013;14:190-3.

8. Patil A, Badade B, Thavare S. Study of neonatal outcome in relation to placental location in tertiary care centre. Med Pulse Int J Gynaecol. 2021;18(1):0914.

9. Cheema HK, Arora R, Joshi H. Study of placental localisation and pregnancy outcome at a medical college in North India. J Evolution Med Dent Sci. 2018;7(09):1136-8.

10. Dhingra S, Premapriya G, Bhuvaneshwari K, Gayathri N, Vimala D. Correlation between placental location and maternal fetal outcome. Obs Rev J obstet Gynecol. 2019;5(3):128-32.

11. Kadium J, Sudha Bindu T. A comparative study of relationship of placental localization by 
ultrasonography in pregnancy induced hypertension and normotensive pregnant women in third trimester. J Evid Based Med. Healthc. 2019;6(49):3081-6.

12. Nair VV, Nair SS, Radhamany K. Study of placental location and pregnancy outcome. Int $\mathbf{J}$ Reprod Contracept Obstet Gynecol. 2019;8:1393-7.

13. Uikey P, Gurwani V, Tajne M. Correlation between placental location and development of preeclampsia. Int J Reprod Contracept Obstet Gynecol. 2019;8:4155-62.

14. Degani S, Leibovitz Z, Shapiro I, Gonen R, Ohel G. Myometrial thickness in pregnancy: Longitudinal sonographic study. J Ultrasound Med. 1998;17(10):661-5.

15. Torricelli M, Vannuccini S, Moncini I, Cannoni A, Voltolini C, Conti $\mathrm{N}$ et al. Anterior placental location influences onset and progress of labor and postpartum outcome. Placenta. 2015;36(4):463-6.
16. Cho JY, Lee YH, Moon MH, Lee JH. Difference in migration of placenta according to the location and type of placenta previa. J Clin Ultrasound. 2008;36(2):79-84.

17. Faizi S, Pai MV. Role of Midtrimester Localization of the Placenta in predicting Pregnancy Outcome. Int $\mathrm{J}$ Infertil Fetal Med. 2014;5(3):87-91.

18. EF Magann, DA Doherty, K Turner, GS Lanneau Jr, JC Morrison and JP Newnham, Second trimester placental location as a predictor of an adverse pregnancy outcome. J Perinatol. 2007;27:9-14.

19. Beune IM, Pels A, Gordijn SJ, Ganzevoort W. Definitions of fetal growth restriction in existing literature over time. Ultrasound Obstet. Gynecol. 2018;53(5):569-70.

Cite this article as: Sitimani A, Sai BP, Narendra SB, Prabhudev P. Study of correlation between fetomaternal outcome with placental location at a tertiary hospital. Int J Reprod Contracept Obstet Gynecol 2022;11:803-7. 